ПЕРСПЕКТИВНЫЕ МОТОРНЫЕ МАСЛА ДЛЯ ДВУХТАКТНЫХ ДВИГАТЕЛЕЙ НА РАСТИТЕЛЬНОЙ ОСНОВЕ

Д-р техн. наук В.А. Войтов, канд. техн. наук А.Г. Кравцов, А.П. Билык, асп. И.И. Сисенко

\title{
ПЕРСПЕКТИВНІ МОТОРНІ ОЛИВИ ДЛЯ ДВОТАКТНИХ ДВИГУНІВ НА РОСЛИННІЙ ОСНОВI
}

Д-р техн. наук В.А. Войтов, канд. техн. наук А.Г. Кравцов, А.П. Білик, асп. I.I. Сисенко

\section{PERSPECTIVE MOTOR OILS FOR TWO-STROKE ENGINES OF PLANT-BASED}

Doctor of science V.A. Vojtov, cand. of techn. sciences A.G. Kravtsov, A.P. Bilyk, graduate student I.I. Sysenko

В работе выполнена сравнительная оценка трибологических свойств высокоолеиновых растительных масел в сравнении с товарными моторными маслами для двухтактных двигателей. Решена оптимизачионная задача по составу присадок в базовых растительных маслах и проведень сравнительные испытания на четырехшариковой машине.

Ключевые слова: растительные масла, присадки для растительных масел, моторные масла для двухтактных двигателей, трибологические свойства растительных масел.

У роботі виконана порівняльна оцінка трібологічних властивостей високоолеїнових рослинних олій в порівнянні з товарними моторними оливами для двотактних двигунів. Вирімена 
оптимізачійна задача по складу присадок в базових рослинних оліях та проведено порівняльні випробування на чотирьохкульковій машині тертя.

Ключові слова: рослинні олї, присадки для рослинних олій, моторні оливи для двотактних двигунів, трібологічні властивості рослинних олій, швидкість зношування, сила тертя.

Comparative evaluation of tribological properties of high oleic vegetable oils compared with commodity motor oils for two-stroke engines was performed. Proposed is quantitative measure of anti-, extreme pressure and anti-friction properties of the oils with the range of the anti-wear and extreme pressure additives. The proposed indicator is a measure of energy and describes the specific work wear. On the basis of the ranking for the integrated energy indicators selected high-oleic canola and sunflower oil as the base for environmentally friendly motor oil for two-stroke engines. The composition of additives in selected base oils for two-stroke engines is substantiated. Optimization problem is solved and the criterion of the maximum value of the specific work of wears, obtained optimum composition of the additives in the base oils. Comparing the tribological properties in accordance found that the production of vegetable oil with additives to $25 \%$ have a higher the critical value load.

Keywords: vegetable oils, additives for vegetable oils, motor oils for two-stroke engines, tribological properties of vegetable oils.

Актуальность проблемы. В странах Западной Европы в последние десятилетия стоит вопрос улучшения экологии в рамках Киотского протокола и последующих принятых директив [1,2]. В результате принятых документов в ЕС построены и запущены заводы по выпуску смазочных материалов, например, в Германии из рапсового масла, а в США из соевого масла.

Всемирно известная фирма SHELL по производству смазочных материалов выпускает биологически разлогаемые смазочные материалы Shell Naturelle Fluid на основе высокоочищенного рапсового масла с присадками [3]. Швейцарская фирма FUCH на основе рапсового масла с многофункциональными присадками выпускает более 150 наименований экологически чистых (быстро разлагаемых) смазочных материалов и технических жидкостей [4].

Особенно остро стоит вопрос о снижении выброса вредных веществ при эксплуатации техники, на которой установлены двухтактные двигатели внутреннего сгорания. Сгоревшее масло вместе с бензином при работе двигателя способствует выбросу вредных веществ в окружающую среду. Если учесть то, что двухтактные двигатели устанавливаются на газонокосилках, скутерах, мотоциклах, бензопилах и моторных лодках, то уровень техногенной нагрузки является достаточно высоким.

Поэтому проведение исследований и разработка моторных масел для двухтактных двигателей на растительной основе является актуальной задачей, которая снизит выброс вредных веществ в окружающую среду.

Анализ последних публикаций по данной проблеме. Первый опыт получения трансмиссионных масел на основе рапсового масла в Украине принадлежит заводу АРIAH [5], который начал использовать присадки на основе растительных масел и добавлять их в минеральные масла. Исследования по получению присадок на основе растительных масел проводятся в УкрНДІНП «МАСМА» [6].

Исследованиями смазочных материалов растительного происхождения в Украине и за рубежом занимались следующие ученые: Поп Г.С. [7-12], Сиренко Г.О. и Кириченко В.И. [13-19], Фукс И.Г. и Евдокимов А.Ю. [20-22], Крачун А.Т. [23].

В работах [7-12] выполнены сравнительные исследования рапсовых масел с различным жирнокислотным составом с нефтяными маслами. Предложено, для улучшения свойств рапсового масла вводить присадки типа Лубризол-890 или отечественные Детерсол-140, Ас-60С и С-5А.

В работах [13-19] исследовались вопросы использования серы в качестве присадки к рапсовому маслу. Показано, что синтезированные продукты с повышенным содержанием серы обеспечивают низкий коэффициент трения и хорошие противоизносные свойства.

В работах [20- 23] рассмотрены вопросы, которые относятся к экологической 
безопасности при использовании смазочных материалов на основе растительных масел.

Авторами работ [24-26] обоснованы и выбраны базовые растительные масла для получения рабочих жидкостей гидростатических приводов. Это высокоолеиновые рапсовое и подсолнечное масла. В указанных работах приведены исследования по противоизносным и противозадирным свойствам этих масел в сравнении с товарными нефтяными и синтетическими. Решена оптимизационная задача по выбору присадок к указанным растительным маслам для их использования в гидростатических приводах.

В работе [27], которая выполнена в Российском государственном университете нефти и газа им. И.М. Губкина, делается вывод, что рапсовое масло может быть основой для получения моторных масел для двухтактных двигателей. При этом для уменьшения кислотного числа рапсового масла и придания ему щелочности, рекомендуется вводить щелочные присадки, содержащие металлы.

Анализируя приведенные выше работы можно сделать вывод, что разработка экологически чистых моторных масел для двухтактных двигателей на растительной основе является актуальной задачей и требует дальнейших исследований.

Поэтому целью данной работы явилось обосновать и выбрать базовые растительные масла, пакет присадок к ним и получить оптимальный состав экологически чистых моторных масел для двухтактных двигателей, а также провести сравнительные испытания их трибологических свойств в сравнении с товарными моторными маслами.
Методический подход в проведении исследований. Трибологические характеристики товарных масел и базовых растительных масел определяли на четырёхшариковой машине трения согласно ГОСТ 9490-75.

В качестве минеральных масел были выбраны масла: «МС-20» и «Такт-2Т», полусинтетическое масло «Пуск-2Т», синтетическое «ELF MOTO 2XT Теch» и три масла на растительной основе: рапсовое, подсолнечное, касторовое.

В качестве трибологических характеристик, согласно ГОСТ 9490-75, были выбраны следующие параметры.

1. Показатель износа $D u$, мм, характеризует в масле наличие противоизносных свойств, в первую очередь, наличие поверхностноактивных веществ (ПАВ).

2. Критическая нагрузка $P_{\kappa p}, \mathrm{H}$, характеризует диапазон работы (действия) ПАВ.

3. Нагрузка сваривания $P_{c}, \mathrm{H}$, характеризует наличие в масле противозадирных свойств.

Дополнительным параметром, который измерялся в процессе эксперимента с помощью тензодатчика, был определен коэффициент трения $f$, характеризующий потери на трение, т.е. антифрикционные свойства.

Согласно работ [24-26] в качестве базовых растительных масел выбраны высокоолеиновое подсолнечное и высокоолеиновое рапсовое масла, а также касторовое масло, которое обладает хорошей физической адгезией к поверхности трения.

Результаты эксперимента представлены в табл. 1. В таблице указаны среднестатистические значения трёх повторов.

Таблица 1

Среднестатистические значения трибологических характеристик товарных моторных и базовых растительных масел

\begin{tabular}{|c|c|c|c|c|}
\hline Тип базового масла & $\begin{array}{c}\text { Показатель } \\
\text { износа Du, мм }\end{array}$ & $\begin{array}{c}\text { Критическая } \\
\text { нагрузка } \mathrm{P}_{\text {кр }}, \mathrm{H}\end{array}$ & $\begin{array}{c}\text { Нагрузка } \\
\text { сваривания } \mathrm{P}_{\mathrm{c}}, \mathrm{H}\end{array}$ & $\begin{array}{c}\text { Коэффициент } \\
\text { трения } \mathrm{f}\end{array}$ \\
\hline МС-20 & 0,9 & 617 & 1568 & 0,05 \\
\hline Такт-2Т & 0,6 & 617 & 1568 & 0,065 \\
\hline Пуск-2Т & 0,47 & 617 & 1568 & 0,06 \\
\hline ELF МОТО 2ХT Tесh & 0,44 & 784 & 1568 & 0,065 \\
\hline Рапсовое масло & 0,44 & 784 & 1568 & 0,055 \\
\hline Подсолнечное масло & 0,45 & 617 & 1568 & 0,055 \\
\hline Касторовое масло & 0,52 & 617 & 1568 & 0,05 \\
\hline
\end{tabular}


Анализ данных табл. 1 позволяет сделать вывод, что все представленные масла обладают одинаковыми противозадирными свойствами (нагрузка сваривания $P_{c}=1568 \mathrm{H}$ ). При этом противоизносные свойства различаются. Диапазон работы ПАВ у синтетического и рапсового масел $\left(P_{k p}=784 \mathrm{H}\right)$, превышает диапазон остальных масел $\left(P_{\kappa p}=617 \mathrm{H}\right)$.

По величине показателя износа, который характеризует противоизносные свойства, можно выделить четыре масла. На первом месте синтетическое маслоELF MOTO 2XT Tech и рапсовое $(D u=0.44 \mathrm{Mm})$, затем подсолнечное $\quad(D u=0,45 \mathrm{~mm}) \quad$ и полусинтетическое Пуск-2Т ( $D u=0,47$ мм). Остальные масла по противоизносным свойствам на $13 \ldots 95 \%$ уступают перечисленным выше маслам.

Однако по антифрикционным свойствам, которые оцениваются коэффициентом трения, табл. 1, высоковязкие масла МC-20 и касторовое, показали лучший результат. При этом, рапсовое, подсолнечное, полусинтетическое и синтетическое масла отличаются от лучшего результата на $16 \%$.

Полученные результаты позволяют сделать вывод, что проранжировать испытуемые масла по четырем показателям одновременно, затруднительно.

В работе [28] предложен количественный показатель противоизносных, противозадирных и антифрикционных свойств масел с учетом диапазона работы противоизносных и противозадирных присадок. Предложенный показатель является энергетическим показателем, размерность Дж/мм ${ }^{3}$ и характеризует удельную работу изнашивания.

Воспользуемся предложенной в работе [28] формулой, предварительно упростив выражение, которое не изменяет физический смысл, а упрощает измерения и вычисления при проведении эксперимента:

$$
E_{y}=\frac{f_{1} P_{1} L_{1}}{D u^{3}}+\frac{f_{\kappa p} P_{\kappa p} L_{2}}{D_{\kappa p}^{3}}+\frac{f_{c-1} P_{c} L_{2}}{D_{c-1}^{3}},
$$

где $f_{1}-$ коэффициент трения при нагрузке $\mathrm{P}_{1}=196 \mathrm{H}$;

$P_{1}$ - нагрузка равная $196 \mathrm{H}$ для определения показателя износа согласно ГОСТ 9490-75;
$L_{1}$ - путь трения при определении показателя износа, равен 1978 м;

$D u$ - средний диаметр пятен износа (показатель износа) при нагрузке 196 Н, мм;

$f_{\kappa p}-$ коэффициент трения при критической нагрузке;

$P_{\kappa p}$ - критическая нагрузка, $\mathrm{H}$;

$L_{2}$ - путь трения при десяти секундах работы четырёхшариковой машины, равен 5,49 м;

$D_{\kappa p}-$ средний диаметр пятен износа при критической нагрузке, мм;

$f_{c-1}$ - коэффициент трения при нагрузке предшествующей нагрузке сваривания;

$P_{c}$ - нагрузка сваривания, $\mathrm{H}$;

$D_{c-1}$ - средний диаметр пятен износа при нагрузке, предшествующей нагрузке сваривания, мм.

Первое слагаемое формулы

отображает противоизносные и

антифрикционные свойства масла, т.е. наличие ПАВ в масле.

Второе слагаемое отображает диапазон работы ПАВ и антифрикционные свойства при критических нагрузках.

Третье слагаемое отображает противозадирные свойства на грани задира.

Предложенный комплексный показатель $E_{y}$, формула (1), является энергетическим

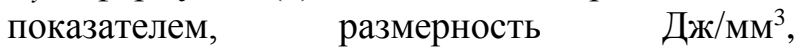
определяется согласно ГОСТ 9490-75 на четырёхшариковой машине в соответствии с нагрузочным рядом и методикой измерения пятен износа на нижних шарах. $E_{y}-$ это удельная работа изнашивания единицы объёма тестового материала (сталь ШХ-15) в испытуемой смазочной среде.

Дополнительно к данным в таблице 1 были проведены измерения коэффициентов трения и пятен износа на критической нагрузке и нагрузке, предшествующей нагрузке сваривания. Результаты испытаний и расчёта по формуле (1) представлены в табл. 2.

Анализ величины удельной работы изнашивания для различных масел позволяет более строго проранжировать испытуемые масла по способности препятствовать износу и задиру. Как следует из табл. 2 на первом месте стоит синтетическое масло ELF MOTO 2XT Tech, затем рапсовое и подсолнечное масла, затем полусинтетическое Пуск-2Т, касторовое и минеральные масла Такт-2Т и МС-20. 
Такой результат позволяет выбрать высокоолеиновые рапсовое и подсолнечное масла - как базовые масла для получения экологически чистых моторных масел для двухтактных двигателей.

Таблица 2

Результаты испытаний и расчёта удельной работы изнашивания в различных маслах

\begin{tabular}{|c|c|c|c|c|}
\hline \multirow{2}{*}{ Тип базового масла } & $\frac{f_{1} P_{1} L_{1}}{D u^{3}}$ & $\frac{f_{\kappa p} P_{\kappa p} L_{2}}{D_{\kappa p}^{3}}$ & $\frac{f_{c-1} P_{c} L_{2}}{D_{c-1}^{3}}$ & \multirow{2}{*}{ Е } \\
& 26590 & 137,2 & 39,2 & 26766 \\
\hline MC-20 & 116665 & 317,7 & 87,2 & 117069 \\
\hline Такт-2T & 225382 & 413,7 & 129,1 & 225924 \\
\hline Пуск-2Т & 296467 & 672,5 & 210,47 & 297349 \\
\hline ELF МОТО 2ХT Тесh & 250856 & 630 & 150,8 & 251636 \\
\hline Рапсовое масло & 234316 & 496,1 & 129,1 & 234941 \\
\hline Подсолнечное масло & 138460 & 276,6 & 62,2 & 138798 \\
\hline Касторовое масло & \multicolumn{2}{|r}{} \\
\hline
\end{tabular}

Обоснование присадок для базовых растительных масел и поиск оптимального состава масла для двухтактных двигателей. Исходя из анализа требований, которые предъявляются к маслам для двухтактных двигателей, а также повышенных значений кислотного числа у растительных масел $(1,5 \ldots$ 2,7 мг КОН/г) одной из присадок выступает антиокислительная, или антиоксидант. Данная присадка позволит приостановить необратимые процессы окисления растительного масла при хранении и даст возможность уменьшить проявление коррозионных процессов, лако- и нагарообразования.

Введение в растительные масла щелочных металлов с целью снижения кислотности и придания щелочности растительному маслу, как указано в работе [27], на наш взгляд не решает проблему. Присутствие щёлочи в высокоолеиновых растительных маслах образует мыла в масле, а так же повысит зольность.

Мыла приведут к лако- и нагарообразованию, а образование золы - к абразивному износу цилиндро-поршневой группы.

В работах выполненных в Российском государственном университете нефти и газа им. И.М. Губкина [27], а также американскими учёнными [29] указывается, что эффективным органическим биоразлогаемым антиоксидантом для растительных масел может выступать дифениламин. При этом в работе [29] указано, что его количество в растительных маслах значительно выше, чем в нефтяных маслах $(0,2 \ldots 5 \%)$. Дифениламин является экологически чистым веществом, т.к. добавляется в пищевые продукты в составе $0,02 \%$ по массе, и не содержит металлов, a, следовательно, не вызовет образования золы и связанного с ней абразивного износа.

Вторым типом присадок для масел двухтактных двигателей является антикоррозионная присадка, которая способствует снижению интенсивности коррозионных процессов на деталях двигателя из-за определенной степени кислотности масла. В качестве органической присадки, не содержащей металлов, на основании работы [30] можно выбрать фосфорсодержащую присадку - трикрезилфосфат. Данная присадка в моторном масле будет выполнять ряд функций:

- тормозить процессы коррозии, т.к. на поверхностях трения будет образовываться фосфидная пленка, уменьшая контакт масла с катализатором - металлом;

- повышать противоизносные и противозадирные свойства масла, образуя на поверхности трения фосфиды металлов.

Третьим типом присадок, добавляемых в растительное моторное масло для двухтактных двигателей, является касторовое масло. В связи с тем, что смазка деталей двухтактного двигателя производится смесью бензина и масла в пропорции от $30: 1$ до 60:1, то бензин 
может смывать масляную пленку с поверхностей трения, обеспечивая работу трибосистем в режиме «масляного голодания», что приведет к снижению ресурса. Устранить режим «масляного голодания» можно обеспечив несмываемость масляной пленки, т.е. масло должно иметь высокую физическую адсорбцию к поверхности металла.

По мнению специалистов фирмы Schell такие требования можно выполнить введением в нефтяные масла касторового масла.

Необходимо отметить, что растительные масла обладают высоким индексом вязкости, который превышает индекс вязкости синтетических масел [16-20]. Такой показатель необходим для двигателей, где масло подается в двигатель отдельно от бензина и смешивается на входе. При эксплуатации в условиях низких температур высокий индекс вязкости будет положительно влиять на смесеобразование, что не требует ввода в растительные масла вязкостных присадок.

В результате планирования трехфакторного эксперимента была решена оптимизационная задача содержания перечисленных присадок в базовых рапсовом и подсолнечном маслах. Критерием оптимизации был выбран максимум удельной работы изнашивания $-E_{y}$.

В дальнейшем будем полученные масла обозначать: рапсовое + П и подсолнечное + П.

Контрольный эксперимент трибологических свойств на четырехшариковой машине согласно ГОСТ 9490-75 полученных масел в сравнение с товарными моторными маслами, показал следующий результат, табл. 3.

Таблица 3

Трибологические характеристики моторных масел для двухтактных двигателей

\begin{tabular}{|c|c|c|c|c|c|}
\hline Тип базового масла & $\begin{array}{c}\text { Показатель } \\
\text { износа Du, } \\
\text { мм }\end{array}$ & $\begin{array}{c}\text { Критическая } \\
\text { нагрузка } \mathrm{P}_{\text {кр }}, \\
\mathrm{H} \\
\end{array}$ & $\begin{array}{c}\text { Нагрузка } \\
\text { сваривания } \\
\mathrm{P}_{c}, \mathrm{H} \\
\end{array}$ & $\begin{array}{c}\text { Коэффи- } \\
\text { циент } \\
\text { трения } \mathrm{f} \\
\end{array}$ & $\begin{array}{c}\text { Удельная работа } \\
\text { изнашивания Е, } \\
\text { Дж/мм }{ }^{3}\end{array}$ \\
\hline Такт-2Т & 0,6 & 617 & 1568 & 0,065 & 117069 \\
\hline Пуск-2Т & 0,47 & 617 & 1568 & 0,06 & 225924 \\
\hline ELF MOTO 2XT Tech & 0,44 & 784 & 1568 & 0,065 & 297349 \\
\hline Рапсовое $+\Pi$ & 0,42 & 980 & 1568 & 0,055 & 294328 \\
\hline Подсолнечное + П & 0,43 & 980 & 1568 & 0,055 & 278520 \\
\hline
\end{tabular}

Анализ табл. 3 в сравнении с данными табл. 1 позволяет сделать следующие выводы.

Противоизносные свойства, которые определяются показателями износа $\mathrm{Du}$, изменились с 0,44 для рапсового масла и 0,45 для подсолнечного масла до значений 0,42 и 0,43, что составляет $4,5 \%$ и $4,4 \%$ соответственно. Такие значения граничат с величиною ошибки определения и не позволяют утверждать изменения противоизносных свойств.

Диапазон работы противоизносных присадок, который определяется величиной критической нагрузки $P_{\kappa p}$, изменился от $784 \mathrm{H}$ до 980 Н для обоих масел, что составляет $25 \%$. Такое увеличение показателя позволяет утверждать, что наряду с физической адсорбцией поверхностно-активных веществ на поверхностях трения имеет место явление хемосорбции.
Следовательно, можно утверждать, что высокомолекулярные жирные кислоты олеиновая и рициновая образуют на поверхностях трения металла металлические мыла, температура плавления которых значительно выше, чем температура десорбции указанных выше кислот, как поверхностноактивных веществ. Данные явления можно объяснить наличием в маслах трикрезилфосфата и касторового масла.

Противозадирные свойства, которые определяются нагрузкой сваривания $P_{c}$, не изменились, что подтверждает отсутствие у трикрезилфосфата и касторового масла противозадирных свойств из-за низкой температуры десорбции.

Антифрикционные свойства растительных масел так же не изменились, т.к. определялись на незначительной нагрузке, $196 \mathrm{H}$.

$$
\text { Однако комплексный показатель, }
$$
удельная работа изнашивания $E_{y}$, которая 
приведена в табл. 2 и табл. 3 увеличилась для рапсового масла с присадками на $16,9 \%$, а для подсолнечного масла на $18,5 \%$.

При этом полученные растительные моторные масла для двухтактных двигателей уступают синтетическому маслу ELF MOTO 2XT Tech, таблица 3, на 6,3\% по комплексному показателю изнашивания $E_{y}$, при этом показывают лучший результат по дифференцированным показателям $D u$ и $P_{\kappa p}$, как отмечалось выше.

\section{Выводы:}

1. Выполнена сравнительная оценка трибологических свойств товарных моторных и базовых растительных масел по ГОСТ 9490-75. Для ранжирования масел предложен комплексный энергетический показатель удельная работа изнашивания единицы объема тестового материала в испытуемой смазочной среде. Удельная работа изнашивания учитывает противоизносные, противозадирные и антифрикционные свойства и позволяет более точно проранжировать масла по способности препятствовать износу и задиру, а также снижать потери на трение. На основании ранжирования по комплексному энергетическому показателю выбраны высокоолеиновые рапсовое и подсолнечное масла, как базовые для получения экологически чистых моторных масел для двухтактных двигателей.

2. Обоснован состав присадок в выбранные базовые растительные масла для двухтактных двигателей. Решена оптимизационная задача и по критерию максимального значения удельной работы изнашивания, получен оптимальный состав присадок в базовых рапсовом и подсолнечном маслах. Сравнением трибологических свойств по ГОСТ 9490-75 установлено, что полученные растительные масла с присадками на $25 \%$ имеют большее значение критической нагрузки. Этому способствуют процессы физической адсорбции и хемосорбции на поверхностях трения.

\section{Список использованных источников}

1. Директива 2003/30/ЄС Європейського Парламенту та Ради про сприяння використанню біологічного палива або інших видів поновлюваного палива для транспорту від 8 травня 2003 року.

2. Директива 2009/28/ЄС від 23 квітня 2009 року «Про стимулювання використання енергії 3 відновлюваних джерел та доповнення та заміну директив 2001/77/СС та 2003/30/СС».

3. Смазочные материалы и технические жидкости «Шелл». Каталог 2011 [Электронный pecypc]. - Режим доступа: URL: http://www.shell.com/ru. - Название с экрана.

4. Екологічно безпечні гідравлічні та змащувальні оливи [Електронний ресурс]. - Режим доступу: URL: http://www.fuchs-oil.com.ua/index.php/oil/eko. - Назва з екрана.

5. Рапсовые «биомасла» [Электорнный ресурс]. - Режим доступа: URL: http://www.newchemistry.ru/printletter.php?n_id=311. - Название с экрана.

6. Научные исследования и разработки пластичных смазок [Электорнный ресурс]. - Режим доступа: URL: http://www.masma.ua. - Название с экрана.

7. Поп, Г.С. Мастильні матеріали з рослинних олій [Текст] / Г.С. Поп // Хімічна промисловість України. - 2006. - № 5. - С. 22-29.

8. Поп, Г.С. Поверхнево-активні речовини та композиційні системи на основі рослинних олій і фосфатидів [Текст] / Г.С. Поп, Л.Ю. Бодачівська, Р.Л. Вечерік // Хімічна промисловість України. 2008. - № 3. - С. 33-37.

9. Поп, Г.С. Стан, перспективи виробництва та застосування палив і мастильних матеріалів із рослинних олій [Текст] / Г.С. Поп // Катализ и нефтехимия. - 2003. - № 12. - С. 21-26.

10. Поп, Г.С. Альтернативні екотехнології і реагенти на основі поновлюваної рослинної сировини [Текст] / Г.С. Поп // Нафтова і газова промисловість України. - 2004. - №1. - С. 61-64.

11. Поп, Г.С. Альтернативні екотехнології і матеріали та устаткування для їх одержання i контролю якості [Текст] / Г.С. Поп, Л.Ю. Бодачівська, В.П. Кисельов // Енергетика. Екологія. Людина: міжнар. Енергоекологічний конгрес, 27-28 бер. 2003р.: праці. - К., 2003. - С. 208-212.

12. Поп, Г.С. Екологічно-сприятливі джерела енергії, мастильні матеріали і поверхнево-активні речовини на рослинній основі [Текст] / Г.С. Поп, Л.Ю. Бодачівска // 1-й Всеукраїнський з’їзд 
екологів: міжнародна науково-практична конференція: зб. матеріалів. - Вінниця: ВНТУ, 2006. C. $149-152$.

13. Антифрикційні властивості полікомпонентних композицій на основі хімічно-модифікованої ріпакової оливи під час мащення пари ароматичний поліамід - сталь [Текст] / Г.О. Сіренко, Л.Я. Мідак, О.В. Кузишин, Л.М. Кириченко, В.І. Кириченко // Полімерний журнал. - 2008. - Т. 30, № 4. - C. 338-344.

14. Сіренко, Г. Рослинні оливи як альтернативні мастильні матеріали і присадки [Текст] / Г. Сіренко, О. Сав'як // Вісник Прикарпат. ун-ту ім. Василя Стефаника. Серія: Хімія. - 2002. - Т. III. C. $117-141$.

15. Кириченко, В.І. Трибоактивація хімічних процесів у нових високоефективних композиціях [Текст] / В.І. Кириченко, Г.О. Сіренко, Л.М. Кириченко // Наукомісткі технології подвійного призначення: тези допов. наук.-практ. конф. - 1994. - С. 76.

16. Сіренко, Г.О. Створення мастильних матеріалів на основі сульфідованої оксиетильованої ріпакової оливи [Текст] / Г.О. Сіренко, О.Л. Сав'як // Десята українська конференції 3 високомолекулярних сполук: тези допов. - 2004. - С.162.

17. Сіренко, Г.О. Оптимізація технології мастильних матеріалів на основі хімічномодифікованої ріпакової оливи [Текст] / Л.М. Кириченко, Г.О. Сіренко // Науковий збірник [«Всеукр. наук. та проф. тов-ва ім. М. Міхновського»]. - 1998. - № 8. - С. 40-47.

18. Кириченко, Л.М. Раціональний метод оптимізації нових мастильних композицій [Текст] / Л.М. Кириченко, Г.О. Сіренко, В.І. Кириченко, В.П. Свідерський // Раціональний експеримент у матеріалознавстві: матеріали 39-го Міжнарод. семінару по моделюванню та оптимізації композитів. 2000. - С. 54-55.

19. Кириченко, В.І. Вітчизняні мастильні матеріали: нові базові компоненти для якісних мастильних композицій [Текст] / В.І. Кириченко, Л.М. Кириченко, Г.О. Сіренко, В.П. Свідерський // Зносостійкість і надійність вузлів тертя машин: міжнарод. наук.-техн. конференц.: тези допов. -2001. - C. 49-51.

20. Фукс, И.,Г. Экологические аспекты использования топлив и смазочных материалов растительного и животного происхождения [Текст] / И.Г. Фукс, А.Ю. Евдокимов, А.А. Джамалов // Химия и технология топлив и масел. - 1992. - № 6. - С. 36-38.

21. Евдокимов, А.Ю. Смазочные материалы на основе растительных и животных жиров [Текст] / А.Ю. Евдокимов, И.Г. Фукс, Л.Н. Багдасаров. - М.: ЦНИИТЭИМС, 1992. - 47 с.

22. Евдокимов, А.Ю. Экологическая безопасность применения топлив и смазочных материалов на базе растительного сырья [Текст] / А.Ю. Евдокимов, И.Г. Фукс, И.Р. Облащикова // Защита окружающей среды в нефтегазовом комплексе. - 2005. - №3. - С. 28-30.

23. Крачун, А.Т. Исследование смазочных свойств некоторых растительных масел [Текст] / А.Т. Крачун, В.У. Морарь, С.В. Крачун // Трение и износ. - 1990. - Т. 11, №5. - С. 929-932.

24. Войтов, В.А. Трібологічні властивості технічних олив на базі соняшникової та ріпакової олій [Текст] / В.А. Войтов, А.Г. Кравцов // Проблеми трибології. - 2011. - № 4. - С. 87-91.

25. Войтов, В. Перспективы использования растительных масел для изготовления смазочных материалов и рабочих жидкостей [Текст] / В. Войтов, А. Кравцов, И. Сысенко // Motrol. - vol. 15, № 7. - 2013. - С. 56-63.

26. Кравцов, А.Г. Підвищення зносостійкості трібосистем гідромашин використанням робочих рідин рослинного походження» [Текст]: автореф. дис... канд. техн. наук: спец. 05.02.04 «Тертя та зношування в машинах» / А.Г. Кравцов. - Харків, 2013. - 20 с.

27. Облащикова, И.Р. Исследование рапсового масла в качестве основы альтернативных смазочных материалов [Текст]: дис. ... канд. техн. наук: 05.17.07 / Облащикова Ирина Рудольфовна. M., 2004. -104 c.

28. Войтов, В.А. Интегральный критерий оценки трибологических свойств смазочных материалов на четырехшариковой машине [Текст] / В.А. Войтов, А.В. Левченко // Трение и износ. 2001. - T. 22, № 4. - C. 441-447.

29. Perez, J. M. et al. «Characterization of Tricresylphosphate Lubricating Films by Micro-Fourier Transform Infrared Spectroscopy.» Tribology Transactions. Jan. 1990: 131-139. 
30. Заславский, Ю.С. Трибология смазочных материалов [Текст] / Ю.С. Заславский. - М.: Химия, 1991. - 240 с.

Войтов Віктор Анатолійович, д-р техн. наук, професор, завідувач кафедри транспортних технологій і логістики, Харківський національний технічний університет сільського господарства ім. П. Василенка. Тел.: (057) 700-38-98. E-mail: ndch_khntusg@mail.ru.

Кравцов Андрій Григорович, канд. техн. наук, доцент кафедри транспортних технологій і логістики,

Харківський національний технічний університет сільського господарства ім. П. Василенка. Тел.: (057) 700-38-98.

E-mail: kravcov_84@mail.ru.

Білик Артем Петрович, канд. техн. наук, кафедра безпеки жіттєдіяльности, Хмельницький національний університет. E-mail: bil2006@yandex.ru.

Сисенко Ігор Іванович, аспірант кафедри транспортних технологій і логістики, Харківський національний технічний університет сільського господарства ім. П. Василенка. Тел.: (057) 700-38-98. E-mail:

ndch_khntusg@mail.ru.

Vojtov V.A., prof., Kharkiv Petro Vasylenko National Technical University of Agriculture. Tel.: (057) 700-38-98 Email: ndch_khntusg@mail.ru.

Kravtsov A.G., Ph.D., Kharkiv Petro Vasylenko National Technical University of Agriculture. Tel.: (057) 700-38-98 Email: kravcov_84@mail.ru.

Bilyk A.P., Ph.D., Khmelnitsky National University.

Sysenko I.I., graduate student, Kharkiv Petro Vasylenko National Technical University of Agriculture. Tel.: (057) 700-

38-98 E-mail: ndch_khntusg@ mail.ru. 